\title{
Relationship of Bovine SLC11A1 (Formerly NRAMP1) Polymorphisms to the Risk of Bovine Tuberculosis in Holstein Cattle
}

\author{
Yafen Cheng MD ${ }^{1,2}$, ChenShen Huang MD ${ }^{1,3}$ and Hsiang-Jung Tsai PHD $^{1,3^{*}}$ \\ ${ }^{*}$ School of Veterinary Medicine, National Taiwan University, No. 1, Sec-4, Roosevelt Rd, Taipei-10617, Taiwan \\ ${ }^{2}$ Centers for Disease Control, Ministry of Health and Welfare, No.6, Linsen S. Rd., Taipei-10050, Taiwan \\ ${ }^{3}$ Animal Health Research Institute, Council of Agriculture, Executive Yuan, No. 376, Zhongzheng Rd, New Taipei City-251, Taiwan
}

"Corresponding author: Hsiang-Jung Tsai PHD, School of Veterinary Medicine, National Taiwan University, No.1, Sec-4, Roosevelt Rd, Taipei-10617, Taiwan, Tel: +886-2-3366-3861; Fax: +886-2-2364-9154; E-mail: tsaihj@ntu.edu.tw

Rec date: Jul 17, 2015; Acc date: Aug 18, 2015; Pub date: Aug 20, 2015

Copyright: ( 2015 Tsai HJ, et al. This is an open-access article distributed under the terms of the Creative Commons Attribution License, which permits unrestricted use, distribution, and reproduction in any medium, provided the original author and source are credited.

\begin{abstract}
Many studies suggest significant genetic variation in the resistance of cattle and humans to infection with Mycobacterium bovis, the causative agent of zoonotic tuberculosis. The natural resistance associated macrophage protein 1 (NRAMP1), encoded by the SLC11A1 gene, plays a key role in the immunological control of a broad spectrum of infectious agents. The aim of the present study was to investigate the influence of single nucleotide polymorphisms (SNPs) of the SLC11A1 gene on bovine tuberculosis (bTB) susceptibility. We genotyped the SLC11A1 gene in 60 bTB-infected Holstein cows and 90 healthy control animals. The influence in the exon 4 and intron 4 regions of SLC11A1 genetic variations on bTB susceptibility was subsequently investigated by association analysis. Our finding demonstrated that the g.107117166A $>\mathrm{G}$ and $\mathrm{g} .107117369 \mathrm{C}>\mathrm{T}$ polymorphisms of the SLC11A1 gene associated with bTB in Holstein cattle. The susceptibility of cattle with the g.107117166A>G genotype compared with the GG genotype was $3.40(95 \% \mathrm{Cl}: 1.10-10.51 ; p=0.048)$ fold higher. The $\mathrm{g}$. $107117166 \mathrm{~A}>\mathrm{G}$ SNP located in the exon 4 of the SLC11A1 gene and the functional consequence was missense. The deduced amino acid sequence for the protein product revealed an alanine to threonine conversion at position 96, which may affect initiation of protein synthesis and disrupt normal NRAMP1 function that protects animals against mycobacterial infection. The other susceptibility of cattle with the g.107117369C>T genotype compared with the TT genotype was 0.26 (95\% Cl: $0.12-0.56 ; p=0.001)$ fold lower. The g.107117369C $>$ T polymorphism, located in the intron 4 of the SLC11A1 gene, may affect elements that control transcription and splicing of the NRAMP1 leading to affect pathophysiological characteristics in tuberculosis. This is the first report showing that the $\mathrm{g}$. 107117166A>G and g.107117369C>T polymorphisms may contribute to SLC11A1-mediated bTB susceptibility.
\end{abstract}

Keywords: Bovine tuberculosis; SLC11A1; Susceptibility

\section{Introduction}

Bovine tuberculosis (bTB) is caused by the intracellular pathogen Mycobacterium bovis (M. bovis), a facultative intracellular parasite of macrophages. This zoonotic infection has a significant economic impact and serious implications for human health, especially in developing countries [1]. Most bTB control programs rely on the intradermal tuberculin skin test (TST) to identify infected cattle, which are then culled [2]. In Taiwan, a national bTB eradication programcomprising an annual TST, restriction of animal movement and slaughter of reactor animals-has been implemented since 1947. Despite these efforts, tuberculosis in animals and humans is still present, and the proportion of TST-positive cattle increased from $0.22 \%$ in 2000 to $0.36 \%$ in 2002 [3]. The failure of the present measures to eradicate $\mathrm{bTB}$ necessitates consideration of additional or complementary control measures.

M. bovis can be transmitted to humans via infectious bacilli through respiratory contact with infected cattle or consumption of unpasteurized dairy products [4]. The host immune response to $M$. bovis infection is complex; following initial exposure, the bacilli are phagocytosed by host macrophages via transporters such as natural resistance-associated macrophage protein 1 (NRAMP1), encoded by the solute carrier family 11 member 1 (SLC11A1) gene. This transporter - which functions as part of the innate immune response plays a key role in inhibiting proliferation of Mycobacterium tuberculosis (M. tuberculosis), through its involvement in acidification of phagosomes [5]. The relationships between various polymorphisms in the human SLC11A1 gene and mycobacterial diseases have been explored, including INT4 (single nucleotide G>C change in intron 4, 469+14G/C, rs3731865), D543N (conservative single base $G>A$ substitution at codon 543, resulting in a change to asparagine from aspartic acid), and 3'UTR TGTG (a deletion in the 3' untranslated region, $1729+55 \mathrm{del}$ ) [6-10]. Additionally, a Taiwanese aboriginal casecontrol study revealed that individuals possessing one of the three polymorphism of the SLC11A1 gene have higher susceptibility to tuberculosis, with those who are heterozygous for the INT4 polymorphism being at greatest risk [6]. Similar findings have also been reported in Chinese, Korean, Japanese, Iranian, AfricanAmerican and Caucasian populations [7-12]. In bovine studies, a genomic region of the $3^{\prime} \mathrm{UTR}$ of the $S L C 11 A 1 \mathrm{cDNA}$ gene sequence is associated with natural resistance against bTB. Polymorphisms in this region (alleles 211, 215 and 217) were associated with a significantly lower incidence of bTB in Zebu (Bos indicus) cattle [13-15]. However, Barthel et al. analyzed 33 cattle (breed unknown) with positive TST results, no association was found between resistance or susceptibility to infection with $M$. bovis and the 3'UTR microsatellite of the SLC11A1 gene [16]. Moreover, recent findings have shown different levels of susceptibility to bTB among various cattle breeds [17-21]. 
Page 2 of 6

Ameni et al. demonstrated high prevalence and increased severity of bTB pathology in Holstein (Bos taurus) compared with Zebu breeds; the risk of bTB in the Holstein breed was more than twice that of Zebu [17]. However, little information is available regarding the association between bTB susceptibility and single nucleotide polymorphisms (SNPs) in the exon 4 and intron 4 regions of the SLC11A1 gene in Holstein cattle. Thus, the aim of the present study was to identify possible associations between SNPs of SLC11A1 and the risk of bTB in Holstein cattle.

\section{Materials and Methods}

\begin{abstract}
Animal studies
Our cohort comprised 150 Holstein cattle in Taiwan, (age range: $0.7-5.0$ years), 60 of which were mandatorily sent to be culled from January of 2011 to December of 2014 after a positive TST, in line with regulations in Taiwan. The remaining 90 control animals, which were frequency-matched to the bTB population in terms of age and gender, were selected from a herd without a recent history of tuberculosis and were TST-negative. All procedures described in this study were reviewed and approved by the National Taiwan University Institutional Animal Care and Use Committee. Subjects with an $M$. bovis positive lymph node were confirmed bTB by culture. Associations between genetic polymorphisms and bTB were examined using a 1:1.5 matched case-control study.
\end{abstract}

\section{Preparation of bovine genomic DNA}

For DNA extraction, 5-10 $\mathrm{ml}$ of peripheral blood was collected from each animal, stored at $-20^{\circ} \mathrm{C}$, taken to the laboratory on dry ice. DNA from the blood samples was extracted using DNeasy Blood \& Tissue Kit (Qiagen, Germantown, MD, USA), according to the manufacturer's instructions. Concentration and purity of the extracted DNA was verified optically using an ND-1000 spectrophotometer (Nanodrop Technology, Wilmington, DL, USA).

\section{Genotyping by polymerase chain reaction}

Polymerase chain reaction (PCR) and direct sequencing analysis were used to detect polymorphisms. Samples for PCR were prepared in a volume of $30 \mu \mathrm{l}$, consisting of $20 \mu \mathrm{l}$ of diethyl pyrocarbonatetreated water, $3 \mu \mathrm{l}$ of $10 \times \mathrm{PCR}$ buffer, $0.5 \mu \mathrm{l}$ of each primer $(10 \mu \mathrm{M}), 2$ $\mu \mathrm{l}$ of $10 \mathrm{mM}$ deoxynucleotide triphosphate (dNTP; Viogene BioTek Corp., New Taipei City, Taiwan), $0.5 \mu \mathrm{l}$ of 2 units/ $\mu l$ Taq DNA polymerase (Viogene BioTek Corp.), and $4 \mu \mathrm{l}$ of the extracted DNA. The forward 5'-TCT CTG GCT GAA GGC CTC TCC-3' and reverse 5'- TGT GCT ATC AGT TTG AGC CTC-3' primers were used for amplifying SLC11A1 fragments, as described previously [21]. The reaction was initiated by heating the mixture to $94^{\circ} \mathrm{C}$ for $5 \mathrm{~min}$, followed by $35 \mathrm{cycles}$ at $94^{\circ} \mathrm{C}$ for $50 \mathrm{~s}, 55^{\circ} \mathrm{C}$ for $1 \mathrm{~min}$, and $72^{\circ} \mathrm{C}$ for 1 min, after which the reaction was concluded with a final extension step at $72^{\circ} \mathrm{C}$ for $10 \mathrm{~min}$. The PCR products were analyzed using $3 \%$ agarose gel electrophoresis. Based on a predicted size of 400 base pairs, products were then sequenced using a BigDye terminator cycle sequencing kit in an Applied Biosystems 3730xl DNA Analyzer (Applied Biosystems, Waltham, MA, USA), using the abovementioned PCR primers.

\section{Statistical methods}

The chi-square test was used to examine the association between genetic polymorphisms and animal's susceptibility to infection. Statistical analyses were performed to compare allelic and genotypic distributions (which were analyzed using R Data Analysis \& Guiding System, http://rweb.tmu.edu.tw/index.php). If the theoretical value for a cell was $<5$ in the chi-square test, Fisher's exact test was applied. The analyses were performed for all the polymorphisms of the gene assessed in this study. For each polymorphism, allelic analyses were performed to determine if animals had a homozygous or heterozygous genotype. To explore possible association between allele or genotype frequencies and infection status of cows, heterogeneity of odds ratios (ORs) for susceptibility to bTB infection was assessed. ORs and 95\% confidence intervals (CIs) were calculated in order to estimate animals' risk of disease. Statistical significance was set at $5 \%(p<0.05)$.

\section{Results}

\section{Polymorphisms in exon 4 and intron 4 of the bovine SLC11A1 gene}

The SNPs including g.107117166A>G, rs458688926, rs449522039 and g.107117369C $>\mathrm{T}$ were identified in exon 4 and intron 4 of the bovine SLC11A1 gene. In order to detect the influence of SLC11A1mediated bTB susceptibility, the following polymorphisms were detected: rs438480308, g.107117166A>G, rs458688926, rs478409125, rs440590557, rs460647173, rs717758716, rs480706808, rs449522039, rs469205385, g.107117369C $>$ T, rs520905988, rs482869550, rs445253274, rs465479809, rs433744578, rs453907967, and rs524557355. In exon 4, the polymorphisms g.107117166 $\mathrm{A}>\mathrm{G}$ and rs458688926 (g.107117167G >C) were identified in both bTB-positive and control cattle. In intron 4, the rs449522039 (g.107117326T >A) and g.107117369C $>$ T SNPs were identified. The influence of genetic variants on bTB susceptibility is presented in Table 1.

\section{Effects of polymorphisms on bTB risk}

The polymorphisms g.107117166A $>\mathrm{G}$ and g.107117369C $>\mathrm{T}$ of the SLC11A1 gene were significantly associated with bTB infection in Holstein cattle. The susceptibility of cattle with the g.107117166A>G genotype compared with the GG genotype was 3.40 (95\% CI: $1.10-10.51 ; p=0.048$ ) fold higher. Furthermore, the A allele was a risk factor for predisposition to bTB (OR: 3.18; 95\% CI: 1.06-9.56; $\mathrm{p}=0.055)$. The susceptibility of cattle with the g.107117369C $>\mathrm{T}$ genotype compared with the TT genotype was 0.26 (95\% CI: $0.12-$ $0.56 ; \mathrm{p}=0.001)$ fold lower. There was a strong association between the $\mathrm{C}$ allele and lower risk of bTB in cattle (OR: 0.56; 95\% CI: 0.34-0.92; $\mathrm{p}=0.030$ ). Our associations remain significant after accounting for multiple testing $(\mathrm{p}=0.008)$. The results demonstrated the implications of g. $107117166 \mathrm{~A}>\mathrm{G}$ and g.107117369C $>\mathrm{T}$ polymorphisms of the SLC11A1 gene on bTB susceptibility in Holstein cattle.

The polymorphisms rs458688926 and rs449522039 of the SLC11A1 gene were not significantly associated with bTB infection in Holstein cattle. The susceptibility of cattle with the rs458688926 genotype compared with the CC genotype was 2.84 (95\% CI: 95\% CI: 0.7910.16; $\mathrm{p}=0.12$ ) fold higher. The susceptibility of cattle with the rs449522039 genotype compared with the AA genotype was 3.07 (95\% CI: $0.27-34.62 ; \mathrm{p}=0.56)$ fold higher. The genotype and allelic distributions of infected and control animals are presented in Tables 2 
Citation: Cheng Y, Huang C, Tsai HJ, (2015) Relationship of Bovine SLC11A1 (Formerly NRAMP1) Polymorphisms to the Risk of Bovine Tuberculosis in Holstein Cattle. J Veterinar Sci Technol 6: 247. doi:10.4172/2157-7579.1000247

Page 3 of 6

and 3. For other SNPs, there were no significant differences between

bTB-positive and control groups.

\begin{tabular}{|c|c|c|c|c|c|c|c|c|}
\hline SNP rs-number & $\begin{array}{l}\text { Chromosome } \\
\text { position } \S\end{array}$ & $\begin{array}{l}\text { Gene } \\
\text { feature }\end{array}$ & genotype & $\begin{array}{l}\text { Gene model } \\
\text { function } \S\end{array}$ & $\begin{array}{l}\text { m RNA } \\
\text { position }^{\S}\end{array}$ & $\begin{array}{l}\text { Allele } \\
\text { change§ }\end{array}$ & $\begin{array}{l}\text { Protein } \\
\text { position } \S\end{array}$ & $\begin{array}{l}\text { Residue } \\
\text { change§ }\end{array}$ \\
\hline rs438480308 & $2: 107117145$ & exon 4 & $\mathrm{CC}$ & missense & 338 & CTG/ATG & 89 & L [Leu]/M [Met] \\
\hline g. $107117166 A>G$ & $2: 107117166$ & exon 4 & GG, AG & missense & 359 & GCC/ACC & 96 & $\mathrm{~A}[\mathrm{Ala}] / \mathrm{T}[\mathrm{Thr}]$ \\
\hline rs458688926 & 2:107117167 & exon 4 & $\mathrm{CC}, \mathrm{CG}$ & missense & 360 & GCC/GGC & 96 & A [Ala]/G [Gly] \\
\hline rs478409125 & $2: 107117180$ & exon 4 & $\mathrm{CC}$ & cds-synon & 373 & GGC/GGG & 100 & G [Gly]/G [Gly] \\
\hline rs440590557 & $2: 107117280$ & intron 4 & $\mathrm{CC}$ & N.D. ${ }^{\neq}$ & 18 & $\mathrm{C} / \mathrm{A}$ & & not found \\
\hline rs460647173 & 2:107117291 & intron 4 & GG & N.D. & 29 & $\mathrm{G} / \mathrm{C}$ & & not found \\
\hline rs717758716 & 2:107117300 & intron 4 & GG & N.D. & 38 & $\mathrm{G} / \mathrm{T}$ & & not found \\
\hline rs480706808 & 2:107117321 & Intron 4 & AA & N.D. & 59 & $\mathrm{~A} / \mathrm{T}$ & & not found \\
\hline rs449522039 & 2:107117326 & intron 4 & AA, AT & N.D. & 63 & $\mathrm{~A} / \mathrm{T}$ & & not found \\
\hline rs469205385 & 2:107117328 & intron 4 & GG & N.D. & 66 & $\mathrm{G} / \mathrm{T}$ & & not found \\
\hline g. $107117369 C>T$ & 2:107117369 & intron 4 & $\mathrm{TT}, \mathrm{TC}$ & N.D. & 107 & $\mathrm{~T} / \mathrm{C}$ & & not found \\
\hline rs520905988 & $2: 107117380$ & intron 4 & GG & N.D. & 118 & $\mathrm{~A} / \mathrm{G}$ & & not found \\
\hline rs482869550 & 2:107117389 & Intron 4 & $\mathrm{AA}$ & N.D. & 127 & $\mathrm{~A} / \mathrm{C}$ & & not found \\
\hline rs 445253274 & 2:107117391 & intron 4 & GG & N.D. & 129 & $\mathrm{G} / \mathrm{T}$ & & not found \\
\hline rs465479809 & $2: 107117392$ & intron 4 & GG & N.D. & 130 & $\mathrm{G} / \mathrm{T}$ & & not found \\
\hline rs433744578 & 2:107117395 & intron 4 & GG & N.D. & 133 & $\mathrm{G} / \mathrm{T}$ & & not found \\
\hline rs453907967 & 2:107117397 & intron 4 & GG & N.D. & 135 & $\mathrm{G} / \mathrm{T}$ & & not found \\
\hline rs524557355 & 2:107117405 & intron 4 & $\mathrm{CC}$ & N.D. & 143 & $\mathrm{C} / \mathrm{T}$ & & not found \\
\hline
\end{tabular}

Table 1: Influence of genetic variants on bovine tuberculosis susceptibility in Holstein cattle. The single-nucleotide polymorphisms (SNP) are located in the exon 4 and intron 4 of bovine $S L C 11 A 1$ gene. ${ }^{\dagger}$ N.D. $=$ not determined. ${ }^{\S}$ source: National Center for Biotechnology Information (NCBI), Database of Single Nucleotide Polymorphisms (dbSNP).

\begin{tabular}{|c|c|c|c|c|c|}
\hline \multirow{2}{*}{ SNP* } & \multirow{2}{*}{ Genotype } & \multicolumn{2}{|l|}{ Allele frequency } & \multirow{2}{*}{$\begin{array}{l}\text { Odds ratio }(95 \% \text { confidence } \\
\text { interval) }\end{array}$} & \multirow{2}{*}{ p-value } \\
\hline & & Infected cattle (No. $/ \%$ ) & Non-infected cattle (No. /\%) & & \\
\hline \multirow[t]{2}{*}{ g. $107117166 A>G$} & GG & $50(83.33)$ & $85(94.44)$ & 1 & \multirow{2}{*}{$0.048^{\neq}$} \\
\hline & GA & $10(16.67)$ & $5(5.56)$ & $3.40(1.10-10.51)$ & \\
\hline \multirow[t]{2}{*}{ rs458688926 } & $\mathrm{CC}$ & $53(88.33)$ & $86(95.56)$ & 1 & \multirow{2}{*}{0.12} \\
\hline & CG & $7(11.67)$ & $4(4.44)$ & $2.84(0.79-10.16)$ & \\
\hline \multirow[t]{2}{*}{ rs449522039 } & AA & $58(96.67)$ & 89 (98.89) & 1 & \multirow{2}{*}{0.56} \\
\hline & AT & $2(3.33)$ & $1(1.11)$ & $3.07(0.27-34.62)$ & \\
\hline g. $107117369 \mathrm{C}>\mathrm{T}$ & TT & $25(41.67)$ & $14(15.56)$ & 1 & $0.001^{\neq}$ \\
\hline
\end{tabular}

Table 2: Frequency distribution of genotypes of SLC11A1 gene in the Mycobacterium bovis infected and non-infected Holstein cattle. ${ }^{\star}$ Singlenucleotide polymorphism. ${ }^{\ddagger} \mathrm{p}<0.05$. 


\begin{tabular}{|c|c|c|c|c|c|}
\hline \multirow[b]{2}{*}{ SNP $^{*}$} & \multirow[b]{2}{*}{ Genotype } & \multicolumn{2}{|l|}{ Allele frequency } & \multirow[t]{2}{*}{ Odds ratio $(95 \%$ confidence interval) } & \multirow[b]{2}{*}{ p-value } \\
\hline & & Infected cattle (No. / \%) & Non-infected cattle (No.\%) & & \\
\hline \multirow[t]{2}{*}{ g. $107117166 A>G$} & G & $110(91.67)$ & $175(97.22)$ & 1.00 & \multirow{2}{*}{0.055} \\
\hline & A & $10(8.33)$ & $5(2.78)$ & $3.18(1.06-9.56)$ & \\
\hline \multirow[t]{2}{*}{ rs458688926 } & C & $113(94.17)$ & 176 (97.78) & 1.00 & \multirow{2}{*}{0.12} \\
\hline & G & $7(5.83)$ & $4(2.22)$ & $2.73(0.78-9.52)$ & \\
\hline \multirow[t]{2}{*}{ rs449522039 } & A & $118(93.33)$ & $179(99.44)$ & 1.00 & \multirow{2}{*}{0.57} \\
\hline & $\mathrm{T}$ & $2(1.67)$ & $1(0.56)$ & $3.03(0.27-33.84)$ & \\
\hline \multirow[t]{2}{*}{ g. $107117369 \mathrm{C}>\mathrm{T}$} & $\mathrm{T}$ & $85(70.83)$ & $104(57.78)$ & 1.00 & \multirow{2}{*}{$0.030^{\ddagger}$} \\
\hline & C & $35(29.17)$ & $76(42.22)$ & $0.56(0.34-0.92)$ & \\
\hline
\end{tabular}

Table 3: Frequency distribution of the alleles of SLC11A1 gene in the Mycobacterium bovis infected and non-infected Holstein cattle. ${ }^{\star}$ Singlenucleotide polymorphism. ${ }^{\ddagger} \mathrm{p}<0.05$.

\section{Discussion}

This study has identified the g.107117166A $>\mathrm{G}$ (conservative single base $A>G$ substitution at codon 96 , resulting in a change to threonine from alanine) and g.107117369C $>\mathrm{T}$ (single nucleotide $\mathrm{C}>\mathrm{T}$ change in intron 4) polymorphisms of the SLC11A1 gene associated with bTB in Taiwan Holstein cattle. Similar findings have also been reported in African Zebu (3'UTR microsatellite polymorphisms of SLC11A1 gene), Chinese Holstein cattle (G1596A SNP of TLR1 gene) and African Buffalo (SNP41 and SNP137 polymorphisms of SLC7A13 and $D M B T 1$ gene) associated with susceptibility to bTB [15,30-31]. NRAMP1 (encoded by the $S L C 11 A 1$ gene) is found in the endosome and phagosome membranes of macrophages and monocytes, and plays a pivotal role in inhibiting proliferation of $M$. tuberculosis through its involvement acidification of phagosomes. Moreover, NRAMP1 regulates the concentrations of divalent cations and nitric oxide, which confer anti-microbicidal actions and contribute to protective immune responses $[4,9]$.

Recent findings have demonstrated significant heritable variation in susceptibility of individual Holstein cattle to bTB, supporting the importance of genetic polymorphisms in ability to control the incidence and severity of bTB outbreaks in animal herds [16,19-20]. Naturally resistant animals had the highest phagocytosis index and showed greater microbial control after exposure to $M$. bovis stimuli, producing stronger pro-inflammatory responses compared with susceptible animals [23]. In seeking to understand the reasons for natural variation in resistance, a high expression of NRAMP1 in peripheral blood cells and tuberculous granulomas from M. bovisinfected cattle appears to support a functional association for the SLC11A1 gene with enhanced protection against mycobacteria $[5,23]$. In bovines, two SLC11A1 alleles have been cloned and mapped to chromosome $2 \mathrm{q} 43$, which corresponds to a region predicted to encode a transmembrane polypeptide molecule that contains a conserved transporter motif and multiple phosphorylation sites [6,13-15]. Kadarmideen and colleagues demonstrated that the polymorphic alleles in the 3'UTR microsatellite of the SLC11A1 gene in Zebu cattle are linked to resistance to bTB. The frequency of the 3'UTR (GT)n microsatellite of the SLC11A1 gene is markedly different between Zebu and Holstein cattle. In Zebu cattle, $\mathrm{GT}_{13}, \mathrm{GT}_{14}, \mathrm{GT}_{13} / \mathrm{GT}_{14}$, and
$\mathrm{GT}_{13} / \mathrm{GT}_{15}$ genotypes were found, while Holstein cattle, in contrast, were homogeneous for genotype (with $100 \%$ of the animals having the $\mathrm{GT}_{13}$ genotype). The pathology was significantly more severe in Holstein compared with Zebu cattle, under identical husbandry conditions $[16,25]$.

Not all studies support an association between SLC11A1 polymorphisms and susceptibility to $M$. bovis infection. Indeed, Barthel and colleagues reported that polymorphic alleles in the 3 'UTR (GT)n microsatellite of the SLC11A1 gene do not affect resistance or susceptibility to infection by $M$. bovis in cattle [24]. Importantly, the susceptible phenotype is due to a nucleotide substitution that results in an amino acid change, rather than polymorphisms in the $3^{\prime} U T R$ (GT)n microsatellite sequences. In addition, it is not completely clear how polymorphisms in the 3'UTR (GT)n microsatellite influence NRAMP1 function [25].

Toward understanding how polymorphisms can lead to functional consequences, Ables et al. identified two nucleotide substitutions in intron 4 of the $S L C 11 A 1$ gene in different cattle [17]. Previous studies on the INT4 polymorphism ( $\mathrm{G}>\mathrm{C}$ change in intron 4$)$ have shown that exon $4 \mathrm{a}$ is encoded by an Alu element within intron 4, resulting in a truncated and hence non-functional NRAMP1[26]. In supporting the importance of the human $S L C 11 A 1$ gene in host defense mechanisms against tuberculosis [8], previous studies support associations between INT4 polymorphisms and bacilli growth (which may affect outcomes in pulmonary tuberculosis) $[7,10,21,27]$. Furthermore, variations in the promoter in linkage disequilibrium with INT4 may regulate the level of normal SLC11A1 mRNA transcribed, and/or the ratio of normal to alternatively spliced product (for example, exon $4 \mathrm{a}$-which was found to be expressed in vivo - would introduce a termination codon in the downstream exon 5, resulting in a severely truncated protein) [26]. Hence, we hypothesized that any variation in exon 4 and intron 4 of the bovine $S L C 11 A 1$ gene that results in a protein sequence change may influence the relative levels of normal and alternatively spliced $S L C 11 A 1$ product. To date, there are only limited data on polymorphisms in exon 4 and intron 4 of the bovine SLC11A1 gene and bTB susceptibility or resistance. 
We sought to determine if there were associations between bTB susceptibility and 4 SNP polymorphisms in exon 4 (rs438480308, rs458688926, rs478409125 and g.107117166A>G), and 14 SNPs polymorphisms in intron 4 of the SLC11A1 gene (rs440590557, rs460647173, rs717758716, rs480706808, rs449522039, rs469205385, rs520905988, rs482869550, rs445253274, rs465479809, rs433744578, rs453907967, rs524557355 and g.107117369C >T). We observed a statistically significant difference for the g.107117166A $>$ G SNP genotype in exon 4 of the SLC11A1 gene, between bTB-infected and non-infected cattle $(\mathrm{p}=0.048)$. Those with the GA genotype had a greater relative risk of acquiring bTB than those with the GG genotype (OR: 3.40; 95\% CI: 1.10-10.51). This result indicates that the GA genotype may increase susceptibility to $\mathrm{bTB}$. The allele frequencies of the susceptibility loci that the A allele of g.107117166A $>\mathrm{G}$ polymorphism compared with the G allele was 3.18 (95\% CI: 1.069.56; $\mathrm{p}=0.055$ ) fold higher. The deduced amino acid sequence for the protein product revealed an alanine to threonine conversion at position 96 (resulting from a codon change from GCC to ACC), which may affect initiation of protein synthesis and disrupt normal NRAMP1 function that protects animals against mycobacterial infection. Previous study has reported that the G1596A SNP in the TLR1 gene is associated with susceptibility to bTB in Chinese Holstein cattle. The reason for this association might be the conversion of isoleucine to valine, which may hinder the recognition of mycobacterial pathogenassociated molecular patterns [29-31]. A similar relationship between SNP41 and SNP137 polymorphisms in the African buffalo (Syncerus caffer) and bTB have been explored. SNP41 occurs in the SLC7A13 gene, and the functional consequence is missense, from isoleucine to valine, which may impact the light chain of heteromeric amino acid transporters. SNP137 is located in the coding region of the Deleted in Malignant Brain Tumour-1 (DMBT1) gene. The functional consequence of SNP137 is missense, from histidine to arginine, which may the pattern recognition receptors [30]. However, the exact mechanism underlying this increased risk remains to be elucidated. Indeed, there are different levels at which increased susceptibility and resistance may be explained, such as resistance to infection or to disease progression. For the g.107117369C $>$ T SNP polymorphism (which results in a $\mathrm{C}$ to $\mathrm{T}$ mutation in intron 4), sequence analyses indicated a lower relative risk for bTB for the TC compared with the TT genotype (OR: $0.26 ; 95 \% \mathrm{CI}: 0.12-0.56 ; \mathrm{p}=0.001$ ). These results indicate that the TC genotype may be protective against bTB. Furthermore, the $\mathrm{C}$ allele of g.107117369C $>\mathrm{T}$ polymorphism compared with the $\mathrm{T}$ allele was 0.56 (95\% CI: 0.34-0.92; $\mathrm{p}=0.030)$ fold lower. Based on previous work [17,26], the g.107117369C>T polymorphism may affect elements that control transcription and splicing of the $S L C 11 A 1$, due to its location within the gene; in turn, this may result in incomplete or inactive proteins. Although the intron 4 polymorphism has no known functional effect, it has been suggested to be in linkage disequilibrium with functional promoter polymorphisms, which may affect pathophysiological characteristics in tuberculosis [26,28-29]. For other polymorphisms (rs438480308, rs458688926, rs478409125, rs440590557, rs460647173, rs717758716, rs480706808, rs449522039, rs469205385, rs520905988, rs482869550, rs445253274, rs465479809, rs433744578, rs453907967, and rs524557355), we found no significant associations with susceptibility to bTB-infection.

\section{Conclusion}

This is the first report to our knowledge that demonstrates the implications of polymorphisms in exon 4 and intron 4 of the SLC11A1 gene on bTB susceptibility in cows. Our data indicate that genetic variations in SLC11A1 exon 4 (g.107117166A $>$ G, which results in an alanine to threonine amino acid change at position 96) and intron 4 (g. $107117369 \mathrm{C}>\mathrm{T}$ ) may contribute to the occurrence and development of $\mathrm{bTB}$, strengthening the hypothesis that polymorphisms in this gene are associated with bTB risk in Holstein cattle. The results from this study have potential for marker-assisted breeding programs. Gene function and association studies in larger populations are still necessary to confirm these findings and to understand the biological mechanism underlying SLC11A1-mediated bTB susceptibility.

\section{Acknowledgements}

The authors thank the members (Chian-Ren Jeng, Dah-Jiun Fu, Hsiu-Luan Chang, Meng-Chieh Hsu, Ming-Chang Lee, and ShyhShyan Liu) who helped to collect the samples. We also thank the researchers (Albert Taiching Liao, Chia-Lan Wang, Chung-Hsi Chou, Fan Lee, Yang-Chi Chiea Fan, and Yu-Chun Liu) for technical help. This research was supported by a grant from the Centers for Disease Control, Taiwan, Republic of China.

\section{References}

1. Etter E, Donado P, Jori F, Caron A, Goutard F, et al. (2006) Risk analysis and bovine tuberculosis, a re-emerging zoonosis. Ann N Y Acad Sci 1081: 61-73.

2. Schiller I, Vordermeier HM, Waters WR, Whelan AO, Coad M, et al. (2010) Bovine tuberculosis: effect of the tuberculin skin test on in vitro interferon gamma responses. Vet Immunol Immunopathol 136: 1-11.

3. Jiang YN (2002) Statics yearbook of animal and plant health inspection and quarantine, Republic of China.

4. Neill SD, Pollock JM, Bryson DB, Hanna J (1994) Pathogenesis of Mycobacterium bovis infection in cattle. Vet Microbiol 40: 41-52.

5. Estrada-Chávez C, Pereira-Suárez AL, Meraz MA, Arriaga C, GarcíaCarrancá A, et al. (2001) High-level expression of NRAMP1 in peripheral blood cells and tuberculous granulomas from Mycobacterium bovisinfected bovines. Infect Immun 69: 7165-7168.

6. Hsu YH, Chen CW, Sun HS, Jou R, Lee JJ, et al. (2006) Association of NRAMP 1 gene polymorphism with susceptibility to tuberculosis in Taiwanese aboriginals. J Formos Med Assoc 105: 363-369.

7. Liu W, Cao WC, Zhang CY, Tian L, Wu XM, et al. (2004) VDR and NRAMP1 gene polymorphisms in susceptibility to pulmonary tuberculosis among the Chinese Han population: a case-control study. Int J Tuberc Lung Dis 8: 428-434.

8. Meilang Q, Zhang Y, Zhang J, Zhao Y, Tian C, et al. (2012) Polymorphisms in the SLC11A1 gene and tuberculosis risk: a metaanalysis update. Int J Tuberc Lung Dis 16: 437-446.

9. Ryu S, Park YK, Bai GH, Kim SJ, Park SN, et al. (2000) 3'UTR polymorphisms in the NRAMP1 gene are associated with susceptibility to tuberculosis in Koreans. Int J Tuberc Lung Dis 4: 577-580.

10. Takahashi K, Hasegawa Y, Abe T, Yamamoto T, Nakashima K, et al. (2008) SLC11A1 (formerly NRAMP1) polymorphisms associated with multidrug-resistant tuberculosis. Tuberculosis (Edinb) 88: 52-57.

11. Velez DR, Hulme WF, Myers JL, Stryjewski ME, Abbate E, et al. (2009) Association of SLC11A1 with tuberculosis and interactions with NOS2A and TLR2 in African-Americans and Caucasians. Int J Tuberc Lung Dis 13: $1068-1076$

12. Wu F, Zhang W, Zhang L, Wu J, Li C, et al. (2013) NRAMP1, VDR, HLA-DRB1, and HLA-DQB1 gene polymorphisms in susceptibility to tuberculosis among the Chinese Kazakh population: a case-control study. Biomed Res Int 2013: 484535.

13. Hasenauer FC, Caffaro ME, Czibener C, Comerci D, Poli MA, et al. (2013) Genetic analysis of the 3' untranslated region of the bovine SLC11A1 gene reveals novel polymorphisms. Mol Biol Rep 40: 545-552. 
Citation: Cheng Y, Huang C, Tsai HJ, (2015) Relationship of Bovine SLC11A1 (Formerly NRAMP1) Polymorphisms to the Risk of Bovine Tuberculosis in Holstein Cattle. J Veterinar Sci Technol 6: 247. doi:10.4172/2157-7579.1000247

Page 6 of 6

14. Horín P, Rychlík I, Templeton JW, Adams LG (1999) A complex pattern of microsatellite polymorphism within the bovine NRAMP1 gene. Eur J Immunogenet 26: 311-313.

15. Kadarmideen HN, Ali AA, Thomson PC, Müller B, Zinsstag J (2011) Polymorphisms of the SLC11A1 gene and resistance to bovine tuberculosis in African Zebu cattle. Anim Genet 42: 656-658.

16. Allen AR, Minozzi G, Glass EJ, Skuce RA, McDowell SW, et al. (2010) Bovine tuberculosis: the genetic basis of host susceptibility. Proc Biol Sci 277: 2737-2745

17. Ameni G, Aseffa A, Engers H, Young D, Gordon S, et al. (2007) High prevalence and increased severity of pathology of bovine tuberculosis in Holsteins compared to zebu breeds under field cattle husbandry in central Ethiopia. Clin Vaccine Immunol 14: 1356-1361.

18. Bermingham ML, More SJ, Good M, Cromie AR, Higgins IM, et al. (2009) Genetics of tuberculosis in Irish Holstein Friesian dairy herds. J Dairy Sci 92: 3447-3456.

19. Biffa D, Bogale A, Godfroid J, Skjerve E (2012) Factors associated with severity of bovine tuberculosis in Ethiopian cattle. Trop Anim Health Prod 44: 991-998.

20. Brotherstone S, White IM, Coffey M, Downs SH, Mitchell AP, et al. (2010) Evidence of genetic resistance of cattle to infection with Mycobacterium bovis. J Dairy Sci 93: 1234-1242.

21. Qu Y, Tang Y, Cao D, Wu F, Liu J, et al. (2007) Genetic polymorphisms in alveolar macrophage response-related genes, and risk of silicosis and pulmonary tuberculosis in Chinese iron miners. Int J Hyg Environ Health 210: 679-689.

22. Castillo-Velázquez U, Gomez-Flores R, Tamez-Guerra R, Tamez-Guerra P, Rodríguez-Padilla C (2013) Differential responses of macrophage from bovines naturally resistant or susceptible to Mycobacterium bovis after classical and alternative activation. Vet Immunol Immunopathol 154: 8-16.
23. Pereira-Suárez AL, Estrada-Chávez C, Arriaga-Díaz C, Espinosa-Cueto P, Mancilla R (2006) Coexpression of NRAMP1, iNOS, and nitrotyrosine in bovine tuberculosis. Vet Pathol 43: 709-717.

24. Barthel R, Piedrahita JA, McMurray DN, Payeur J, Baca D, et al. (2000) Pathologic findings and association of Mycobacterium bovis infection with the bovine NRAMP1 gene in cattle from herds with naturally occurring tuberculosis. Am J Vet Res 61: 1140-1144.

25. Paixão TA, Ferreira C, Borges AM, Oliveira DA, Lage AP, et al. (2006) Frequency of bovine Nramp1 (Slc11a1) alleles in Holstein and Zebu breeds. Vet Immunol Immunopathol 109: 37-42.

26. Cellier M, Govoni G, Vidal S, Kwan T, Groulx N, et al. (1994) Human natural resistance-associated macrophage protein: cDNA cloning, chromosomal mapping, genomic organization, and tissue-specific expression. J Exp Med 180: 1741-1752.

27. Zhang W, Shao L, Weng X, Hu Z, Jin A, et al. (2005) Variants of the natural resistance-associated macrophage protein 1 gene (NRAMP1) are associated with severe forms of pulmonary tuberculosis. Clin Infect Dis 40: $1232-1236$.

28. Ables GP, Nishibori M, Kanemaki M, Watanabe T (2002) Sequence analysis of the NRAMP1 genes from different bovine and buffalo breeds. J Vet Med Sci 64: 1081-1083.

29. Möller M, Hoal EG (2010) Current findings, challenges and novel approaches in human genetic susceptibility to tuberculosis. Tuberculosis (Edinb) 90: 71-83.

30. le Roex N, Koets AP, van Helden PD, Hoal EG (2013) Gene polymorphisms in African buffalo associated with susceptibility to bovine tuberculosis infection. PLoS One 8: e64494.

31. Sun L, Song Y, Riaz H, Yang H, Hua G, et al. (2012) Polymorphisms in toll-like receptor 1 and 9 genes and their association with tuberculosis susceptibility in Chinese Holstein cattle. Vet Immunol Immunopathol 147: 195-201. 